\title{
Observation of the out-coupling of a nematicon
}

\author{
Jeroen Beeckman ${ }^{1}$, Kristiaan Neyts ${ }^{1}$, Xavier Hutsebaut ${ }^{2}$, \\ Marc Haelterman ${ }^{2}$ \\ ${ }^{1}$ Liquid Crystals \& Photonics group, Elis Department, Ghent University, Sint- \\ Pietersnieuwstraat 41,9000 Gent, Belgium, jeroen.beeckman@elis.ugent.be \\ ${ }^{2}$ Service d'optique et acoustique, Université libre de Bruxelles CP 194/5, 50 avenue \\ F.D. Roosevelt, 1050 Bruxelles, Belgium
}

\section{Keywords: Spatial solitons, optical nonlinearity, beam characteristics}

Spatial optical solitons in nematic liquid crystals are called nematicons [1]. They occur due to the nonlinear self-focusing of an optical beam, injected laterally into a liquid crystal cell. The origin of the self-focusing can either be thermal or reorientational. In the latter case, the molecules are reoriented by the electric field of the light, which in turn changes the refractive index and causes the self-focusing. Since their first observation, the properties of these nematicons have been studied extensively in different geometries, both experimentally, theoretically and numerically. The experiments, however, are always based on the observation of the beam via scattering or by visualizing the self-induced waveguide via transverse light propagation [2]. The observation of the beam via out-coupling has not yet been investigated for a planar geometry.

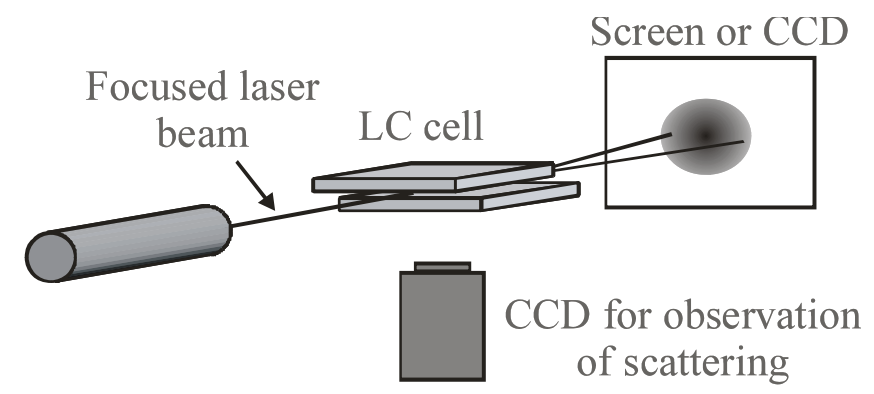

Figure 1. Set-up for simultaneous measurement of the soliton propagation in the cell and the outcoupling of this beam

In this work we present the simultaneous observation of the beam propagation in the cell (observed via scattering) and the out-coupling of the beam. This allows us to draw conclusions of how the beam is actually propagating in the cell. One important observation is the lateral displacement of the beam on the screen due to the transverse undulation of the beam inside the cell. This undulation is caused by the anisotropic walk-off of the beam as reported earlier in $[3,4]$. The displacement is in good agreement with the values of the undulation earlier reported.

\section{References}

[1] G. Assanto, M. Peccianti, C. Conti, Nematicons: Optical Spatial Solitons in Nematic Liquid Crystals, Opt. Phot. News 14 (2), pp. $44-48$ (2003). 
[2] X. Hutsebaut, C. Cambournac, M. Haelterman, J. Beeckman, K. Neyts, Measurement of the Self-induced Waveguide of a Solitonlike Optical Beam in a Nematic Liquid Crystal, J. Opt. Soc. Am. B 22, pp. 1424-1431(2005).

[3] J. Beeckman, K. Neyts, X. Hutsebaut, C. Cambournac, M. Haelterman, Simulation of 2-D Lateral Light Propagation in Nematic-liquid-crystal Cells with Tilted Molecules and Nonlinear Reorientational Effect, Opt. Quant. Electron. 35, pp. 95-106 (2005).

[4] M. Peccianti, A. Fratalocchi, G. Assanto, Transverse Dynamics of Nematicons, Opt. Express 12, pp. 6524-6529 (2004).

Acknowledgments: J. Beeckman is research assistant of the Fund for Scientific Research Flanders. We aknowledge the PhotonNetwork of the Belgian Science Policy and we would also like to acknowledge Per Rudquist and Koen d'Havé for the preparation of the glass plates. 